\section{POS0610 EPIDEMIOLOGIC PROFILE AND CHANNELING TO TREATMENT IN RHEUMATOID ARTHRITIS PATIENTS TREATED WITH ABATACEPT OVER THE LAST 5 YEARS: DATA FROM THE SPANISH REGISTER BIOBADASER 3.0}

S. C. Rodriguez-García ${ }^{1}$, C. Sánchez-Piedra², R. Castellanos-Moreira ${ }^{3}$, D. RuizMontesinos ${ }^{4}$, M. Pombo ${ }^{5}$, F. Sánchez-Alonso ${ }^{2}$, J. J. Gómez-Reino ${ }^{6}$ on behalf of the BIOBADASER Working group. ${ }^{1}$ Hospital de La Princesa, Rheumatology, Madrid, Spain; ${ }^{2}$ Spanish Society of Rheumatology (SER), Research Unit, Madrid, Spain; ${ }^{3}$ Hospital Clínic de Barcelona, Rheumatology, Barcelona, Spain; ${ }^{4}$ Hospital Universitario Virgen Macarena, Rheumatology, Sevilla, Spain; ${ }^{5}$ Hospital Clínico Universitario de Santiago, Rheumatology, Santiago de Compostela, Spain; ${ }^{6}$ Fundación IDIS, Rheumatology, Madrid, Spain

Background: Abatacept $(\mathrm{ABA})$ is a selective T-cell co-stimulatory modulator. After its approval, changes in therapeutic recommendations, the arrival of new drugs (e.g., biosimilars or Janus kinase inhibitors) and growing focus on comprehensive patient care may have changed prescription patterns, channeling ABA use towards specific patient subtypes. To date, studies analyzing these aspects in clinical practice settings are scarce.

Objectives: We aimed to evaluate the epidemiological profile of ABA users and compare it to other DMARD groups included in the register.

Methods: We performed an observational study based on the nationwide Spanish register BIOBADASER, which includes patients with rheumatic diseases receiving biologic disease-modifying antirheumatic drugs (bDMARDs) or targeted synthetic DMARDs (tsDMARDs) from 28 tertiary centers. For this analysis, all RA patients included from December 2015 to December 2020 were examined. Baseline features were analyzed descriptively grouping all b/tsDMARDs by mode of action. Clinical effectiveness was assessed through drug survival obtained by the Kaplan-Meier method. Patients were right-censored if data were not available if they were still on treatment at the time of data analysis. The safety profile was assessed by the adverse events (AE) and serious $A E$ incidence rates (IR) expressed as events per 1000 patient-years.

Results: There were 628 ABA-treated patients, $471(75 \%)$ using the subcutaneous presentation. Only $142(23 \%)$ were on first-line while $381(61 \%)$ were on third or later-line therapy. ABA users were older and more likely to present certain comorbidities compared to the other b/tsDMARD groups. The biggest relative differences were seen for interstitial lung disease (ILD), chronic obstructive pulmonary disease (COPD), diabetes and ischemic heart disease. (Table 1)

Table 1.

\begin{tabular}{lccccc}
\hline $\mathrm{N}$ & ABA & IL-6 & CD20 & JAKi & TNFi \\
\cline { 2 - 6 } & 628 & 786 & 181 & 669 & 1787 \\
Mean age, years (SD) & $64.1(12.0)$ & $50.7(12.7)$ & $63.2(12.3)$ & $59.6(12.3)$ & $60.7(13.1)$ \\
Female sex, n (\%) & $482(77)$ & $652(83)$ & $135(75)$ & $537(80)$ & $1418(79)$ \\
Median disease duration & 10.1 & 9.4 & 13.3 & 10.4 & 7.4 \\
$\quad(p 25-p 75)$ & $(5.1-16.5)$ & $(4.6-15.9)$ & $(8.3-20.6)$ & $(5.0-17.2)$ & $(3.2-13.7)$ \\
ACPA, n (\%) & $352(72)$ & $425(71)$ & $113(79)$ & $407(70)$ & $875(70)$ \\
RF, n (\%) & $380(77)$ & $454(75)$ & $124(86)$ & $411(70)$ & $915(72)$ \\
Current smokers, n (\%) & $98(16)$ & $137(17)$ & $338(19)$ & $90(20)$ & $259(18)$ \\
ILD, n (\%) & $64(13)$ & $21(3)$ & $25(2)$ & $8(2)$ & $19(2)$ \\
COPD, n (\%) & $38(6)$ & $23(3)$ & $52(3)$ & $14(3)$ & $43(3)$ \\
Chronic Kidney Disease, n (\%) & $18(3)$ & $13(2)$ & $19(1)$ & $13(3)$ & $18(1)$ \\
Diabetes & $73(12)$ & $66(8)$ & $13(7)$ & $46(10)$ & $100(7)$ \\
Ischemic Heart Disease, n (\%) & $36(6)$ & $23(3)$ & 0 & $12(3)$ & $30(2)$ \\
Hypertension, n (\%) & $197(31)$ & $198(25)$ & $416(23)$ & $131(30)$ & $338(23)$ \\
Heart Failure, n (\%) & $19(4)$ & $12(2)$ & $10(1)$ & $6(2)$ & $5(1)$ \\
Osteoporosis, n (\%) & $133(21)$ & $141(18)$ & $26(14)$ & $72(16)$ & $215(15)$
\end{tabular}

L-6: Tocilizumab and Sarilumab; CD20: Rituximab and biosimilars; JAKi: Janus kinase inhibitors (Tofacitinib and Baricitinib); TNFi: TNF inhibitors and biosimilars; ACPA: anti-citrullinated peptide antibodies; RF: rheumatoid factor; ILD: interstitial lung disease; COPD: chronic obstructive pulmonary disease.

Overall, $63 \%$ of patients remained on ABA at 1 year, $48 \%$ at 2 and $31 \%$ at 5 years after drug initiation. The corresponding proportions were $79 \%, 65 \%$ and $52 \%$ for bionaïve and $59 \%, 43 \%$ and $30 \%$ for those in third or later-line therapy. From 394 total discontinuations, loss of efficacy in $225(57 \%)$ and AE in $98(25 \%)$ were the main reasons. This trend was consistent among all therapy lines.

The total IR of AE was 886.5 (837.3-938.5) and 156.4 (136.5-179.2) for SAE. Infections were the most frequent AE overall, IR 44.4 (34.4-57.3), and the highest IR was seen among bionaïve patients (69.6 (44.9-107.9)).

Conclusion: ABA-treated RA patients in Spain are older and have more comorbidities (vs other b/tsDMARDs), especially ILD, COPD, ischemic heart disease and diabetes and receive $A B A$ as third or later-line therapy. Although these features are associated with worse response to treatment and a higher risk of infection, $A B A$ presents a good drug survival and infectious $A E$ are not the main cause of discontinuation

Acknowledgements: On behalf of the BIOBADASER Working group
Disclosure of Interests: Sebastián C Rodriguez-García Speakers bureau: Sanofi, MSD, UCB-Pharma, Bristol-Myers-Squibb, Novartis, Janssen, Consultant of: Bristol-Myers-Squibb, Galápagos, Carlos Sánchez-Piedra: None declared, Raul Castellanos-Moreira Speakers bureau: Roche, Sanofi, MSD, UCB-Pharma, Bristol-Myers-Squibb, Novartis, Lilly, and Pfizer., Dolores Ruiz-Montesinos: None declared, Manuel Pombo: None declared, Fernando Sánchez-Alonso: None declared, Juan J. Gómez-Reino Consultant of: Pfizer, Grant/research support from: Abbvie, Lilly, MSD, Pfizer, Roche, and UCB.

DOI: 10.1136/annrheumdis-2021-eular.1534

\section{POS0611 THE EFFECT OF RITUXIMAB BIOSIMILAR THERAPY ON THE EXPRESSION OF INTERFERON-STIMULATED GENES (“INTERFERON SIGNATURE”) IN PATIENTS WITH RHEUMATOID ARTHRITIS}

A. Avdeeva ${ }^{1}$, E. Tchetina ${ }^{2}$, G. Markova ${ }^{2}$, E. Nasonov ${ }^{2} .{ }^{1}$ V.A. Nasonova Research Institute of Rheumatology, Early Arthritis Laboratory, Moscow, Russian Federation; ${ }^{2}$ V.A. Nasonova Research Institute of Rheumatology, Early Arthritis Laboratory, Moscow, Russian Federation

Background: Type I interferons (IFN-Is) are a group of molecules with pleiotropic effects on the immune system forming a crucial link between innate and adaptive immune responses. The type I interferon pathway has been implicated in the pathogenesis of a number of rheumatic diseases, including rheumatoid arthritis. IFN activity is usually quantified using expression of interferon-stimulated genes (ISGs) referred to as an IFN signature. Acellbia (BIOCAD) is the first Russian rituximab (RTX) biosimilar which was approved for medical use in rheumatoid arthritis (RA) patients in Russia and some CIS countries.

Objectives: To evaluate the changes in expression of ISGs in patients (pts) with RA during RTX biosimilar therapy

Methods: 20 RA pts (18 woman, Me;IQR age 61.5(54-66.5) years, disease duration 39.5(20-84) months, mean DAS 28 5.6(4.9-6.8)) received two intravenous RTX biosimilar infusions (600 mg №2) in combination with DMARDs and glucocorticoids. Laboratory biomarkers were assessed at baseline and 24 weeks after the first infusion of RTX. 5 genes (IFI44L, MX1, IFIT 1, RSAD2, EPSTI1) were selected for evaluation of the "interferon signature" (Type I IFN gene signature IFNGS). IFI44L and IFIT1 expression was undetectable, therefore the remaining three genes (MSX1, EPSTI1, RSAD2) were included into further analysis. IFNGS was calculated as the average expression values of the three selected genes. The control group included 20 age and gender matching healthy donors. Results: The baseline expression levels of MX1-11.48 (5.45-19.38), EPSTI1-12.83 (5.62-19.64), RSAD2-5.16 (2.73-10.4), and IFNGS-10.3 (5.18-17.12) in RA patients were significantly higher compared to healthy donors- $1,26(0,73-1,6) ; 1,06(0,81$ $1,48) ; 0,93(0,72-1,19) ; 1,09(0,92-1,42)$, $(p<0.05$, respectively). IFNGS was detected in $15(75 \%)$ patients, and was not found in $5(15 \%)$ patients. RTX induced reduction in disease activity, and the level of acute phase reactants (ESR, CRP) after 12 and 24 weeks of therapy, $p<0.05$ (fig. 1$)$. Increased RSAD 2 expression $(p<0.05)$ and a trend to increasing IFNGS levels $(p=0.06)$ were documented in the whole group, and also in patients with moderate treatment effects by week 24 . Among patients with a good EULAR response to therapy, changes in expression were not significant ( $p>0.05$ ) (fig.1)

\begin{tabular}{|c|c|c|c|c|}
\hline Parameters & Week & $\begin{array}{l}\text { Patients with RA } \\
(n=20)\end{array}$ & $\begin{array}{l}\text { Moderate no EULAR } \\
\text { response by week } 24 \\
(\mathrm{n}=15)\end{array}$ & $\begin{array}{c}\text { Good EULAR } \\
\text { response by wedk } 24 \\
(\mathrm{n}=5)\end{array}$ \\
\hline \multirow[t]{2}{*}{ DAS 28} & \multirow{2}{*}{$\begin{array}{l}\text { baseline } \\
\text { week } 12\end{array}$} & $5.6(4.9-6.8)$ & $5.64(4.68-6.99)$ & $5.6(5.2-6.57)$ \\
\hline & & $4.28(3.24-4.75)$ & $4.4(3.3-5.05)^{*}$ & $4.17(2.6-4.4)^{*}$ \\
\hline \multirow[b]{2}{*}{$\mathrm{ESR}, \mathrm{mm} / \mathrm{h}$} & \multirow{2}{*}{$\begin{array}{l}\text { week } 24 \\
\text { baseline }\end{array}$} & $4.14(3.11-4.66)$ & $4.47(3.8-4.8)^{*}$ & $2.5(2.33-2.6)^{*}$ \\
\hline & & $45.0(19.5-80.0)$ & $50.0(14.0-87.0)$ & $40.0(40.0-70.0)$ \\
\hline \multirow{5}{*}{$\mathrm{CRP} \mathrm{mg} / \mathrm{ml}$} & week 12 & $20.0(16.0-38.0)^{*}$ & $22.0(18.0-40.0)^{*}$ & $16.0(12.0-18.0)^{*}$ \\
\hline & week 24 & $21.5(12.0-31.0)^{*}$ & $28.0(14.0-36.0)$ & $12.0(10.0-12.0)^{*}$ \\
\hline & baseline & $12.3(8.9-45.2)$ & $14.4(9.2-46.0)$ & $10.2(8.6-37.1)$ \\
\hline & week 12 & $4.9(2.2-11.3)^{\circ}$ & $5.7(2.4-13.3)^{\circ}$ & $39(1.6-5.1)^{*}$ \\
\hline & week 24 & $4.9(2.3-21.9)^{\circ}$ & $10.4(2.7-24.1)$ & $2.6(1.2-4.2)^{*}$ \\
\hline \multirow[t]{2}{*}{ EPST1 } & \multirow{2}{*}{$\begin{array}{l}\text { baseline } \\
\text { week } 24\end{array}$} & $12.83(5.62-19.64)$ & $13.1(5.4-19.9)$ & $12.6(9.8-14.2)$ \\
\hline & & $14.4(3.38-43.9)$ & $12.4(2.9-49.5)$ & $16.4(10.3-19.9)$ \\
\hline \multirow[t]{2}{*}{ RSAD2 } & \multirow{2}{*}{$\begin{array}{l}\text { baseline } \\
\text { week } 24\end{array}$} & $5.16(2.73-10.4)$ & $5.12(2.3-9.7)$ & $8.34(3.7-18.2)$ \\
\hline & & $14.97(5.04-42.1)^{*}$ & $14.6(1.3 .43 .9)^{4}$ & $15.4(59-40.3)$ \\
\hline \multirow[t]{2}{*}{ MX1 } & \multirow{2}{*}{$\begin{array}{l}\text { baseline } \\
\text { week } 24\end{array}$} & $11.48(5.45-19.38)$ & $10.6(5.3-18.8)$ & $13.5(5.8-19.9)$ \\
\hline & & $12.49(3.4-69.1)$ & $10.4(3.2-80.4)$ & $56.5(9.7-57.7)$ \\
\hline \multirow[t]{2}{*}{ IFNGS } & \multirow{2}{*}{$\begin{array}{l}\text { baseline } \\
\text { week } 24\end{array}$} & $10.3(5.18-17.12)$ & $11.7(4.4-18.9)$ & $8.9(8.3-15.3)$ \\
\hline & & $\begin{array}{c}16.5(5.05-55.8) \\
p=0,06\end{array}$ & $\begin{array}{c}14.8(2.8-60.8), \\
p=0,06\end{array}$ & $.4(11.6-38$ \\
\hline
\end{tabular}

* $p<0.05$ from baseline

\section{Figure 1.}

Conclusion: Expression of IFN-stimulated genes was increased in RA patients compared to healthy donors. Increased RSAD2 and IFNGS expression was documented in patients with moderate effect of RTX therapy, therefore, these findings have important clinical relevance as predictors of RA clinical course which necessitates personified approach to treatment.

Disclosure of Interests: None declared

DOI: 10.1136/annrheumdis-2021-eular.155 